\title{
Characteristics Buton Natural Asphalt-Rubber (BNA-R) on the Performance Improvement of Warm Mix Asphalt Using Natural Zeolite
}

\author{
Nurul Wahjuningsih ${ }^{1,2, *}$, Sigit Pranowo Hadiwardoyo ${ }^{1}$, and $R$ Jachrizal Sumabrata $^{1}$ \\ ${ }^{1}$ Civil Engineering Department, Universitas Indonesia, Depok, Indonesia \\ ${ }^{2}$ Civil Engineering Department, Institut Teknologi Bandung, Bandung, Indonesia
}

\begin{abstract}
The decrease in the ability of service of pavement can be caused by the durability factor in the pavement layer in receiving heavy traffic load and the temperature of the pavement. Permanent deformation is one of the criteria of failure of asphalt mixture. Performance assessment of the asphalt mixture can be observed from the rheological properties of asphalt binder. The use of BNA-R in this study is intended to modify the characteristics of bitumen penetration grade $60 / 70$ used in warm mix asphalt. Warm mix asphalt with lower temperatures of mixing and compaction than conventional asphalt mixtures was chosen because it is more environmentally friendly. To reduce the temperature in this warm asphalt technology is achieved by using natural zeolite. Both of these materials are local materials that are widely available in Indonesia. The rheology of asphalt $60 / 70$ modified with BNA-R indicates that the addition of BNA-R in the base asphalt increase the complex modulus value and decrease the phase angle value. These values were related to the performance of mixture in the permanent deformation criteria. Reducing the temperature of mixing and compaction should be balanced with modifying the asphalt binder used. Rutting due to permanent deformation can resulted in inconvenience to the passengers and can lead to high costs of road maintenance. To determine the permanent deformation of asphalt mix with material combinations was performed through the wheel tracking test machine with 3,780 cycles for 3 hours. The results shows that after test track over 7 thousand passes have seen permanent deformation characteristics of asphalt concrete mixture with a variation of the characteristics of bitumen.
\end{abstract}

\section{Introduction}

Permanent deformation is one of failure criteria of asphalt mixture [1]. On the pavement layer this condition will cause inconvenience of user roads and high cost maintenance. With the increase in traffic load and tire pressure, most of the permanent deformation occurs in the upper layers [1-2]. The improvement of permanent deformation of asphalt pavement layer will be important things to enhance the convenience of user road.

* Corresponding author: nwahjuningsih@gmail.com 
Warm Mix Asphalt (WMA) is one of innovation in the manufacturing of asphalt mixture that reduce the mixing and compaction temperature about $20-40^{\circ} \mathrm{C}$ with involve the organic additives, chemical additives and water-based or water-containing processes [3], [4]. Many advantages of WMA as reported the researcher like reduced emission, lower energy consumption in production of asphalt mixture, better working condition because absence of harmful gasses, longer hauling distances, and extended paving window. Besides, the drawbacks of this mixture still found such are higher costs because there is still a certain reticence to using them, lack of data concerning their long-term performance, greater moisture susceptibility due to lower temperatures and coating and bonding problems [3], [5].

In the laboratory, the simulation of the deformation caused by wheel load were performed using wheell tracking test because this test could model the stress of pavement at the field [6]. Generally, the testing was done in the 1,260 trajectories or in 1 hour. The studies have been conducted showed that this trajectories number has limitation for advanced analysis. The result of the one hour cycle has not reached the secondary zone which the accumulation of permanent deformation has not occurred, so that increasing the number of cycle more than 1 hour is required [7].

This study aims to characterize the properties of bitumen samples involving BNA-R with the different content and knowing the influence to the permanent deformation of warm mix asphalt. For this purpose, conventional test methods as well as dynamic shear rheometer test at different temperatures have been performed to the base bitumen and modified bitumen.

\section{Material and methods}

Bitumen base used in this research was asphalt cement with penetration grade 60/70 which fulfilled Indonesian specification. The characteristics of base bitumen have shown in the Table 1.

Table 1. Characteristics of base bitumen.

\begin{tabular}{|c|l|c|c|c|c|}
\hline No & \multicolumn{1}{|c|}{ Laboratory Test } & Method & Unit & $\begin{array}{c}\text { Indonesian } \\
\text { Specification }\end{array}$ & $\begin{array}{c}\text { Bitumen } \\
\text { Penetration } \\
\text { Grade } \\
\mathbf{6 0} / 70\end{array}$ \\
\hline 1 & Penetration at $25^{\circ} \mathrm{C}$ & ASTM-D5 & $0.1 \mathrm{~mm}$ & $60-70$ & 64.2 \\
\hline 2 & Softening Point & ASTM-D36 & ${ }^{\circ} \mathrm{C}$ & $\geq 48$ & 51.5 \\
\hline 3 & Flash Point $(\mathrm{Cleveland})$ & ASTM-D92 & ${ }^{\circ} \mathrm{C}$ & $\geq 232$ & 338 \\
\hline 4 & Ductility at $25^{\circ} \mathrm{C}$ & ASTM-D113 & $\mathrm{cm}$ & $\geq 100$ & $>100$ \\
\hline 5 & Specific Gravity at $25^{\circ} \mathrm{C}$ & ASTM-D70 & $\mathrm{kg} / \mathrm{m} 3$ & $\geq 1.0$ & 1.037 \\
\hline 6 & Penetration after TFOT & ASTM-D5 & $0.1 \mathrm{~mm}$ & $\geq 54$ & 61.3 \\
\hline 7 & Kinematic Viscosity at $135^{\circ} \mathrm{C}$ & ASTM-D2170-67 & $\mathrm{cSt}$ & $\geq 300$ & 459.6 \\
\hline
\end{tabular}

The aggregate consisted of coarse, medium and fine aggregate with the largest size of $19 \mathrm{~mm}$ and the composition of aggregate gradation shown in Table 2. The properties of each aggregates are shown in Table 3. And the sample of asphalt mixture was prepared for the AC-WC (Asphalt Concrete Wearing Course) type based on Indonesian specification 3rd revision 2010. 
Table 2. Gradation of AC-WC.

\begin{tabular}{|cc|c|}
\hline \multicolumn{2}{|c|}{ Sieve Size } & \% passing \\
\hline $3 / 4$ in & $(19.1 \mathrm{~mm})$ & 100 \\
\hline $1 / 2$ in & $(12.7 \mathrm{~mm})$ & 95 \\
\hline $3 / 8$ in & $(9.52 \mathrm{~mm})$ & 83.5 \\
\hline No. 4 & $(4.76 \mathrm{~mm})$ & 61 \\
\hline No. 8 & $(2.38 \mathrm{~mm})$ & 43 \\
\hline No. 16 & $(1.18 \mathrm{~mm})$ & 30.5 \\
\hline No. 30 & $(0.59 \mathrm{~mm})$ & 22 \\
\hline No. 50 & $(0.279 \mathrm{~mm})$ & 15.5 \\
\hline No. 100 & $(0.149 \mathrm{~mm})$ & 10.5 \\
\hline No. 200 & $(0.074 \mathrm{~mm})$ & 6.5 \\
\hline \multicolumn{3}{|c|}{} \\
\end{tabular}

Table 3. Aggregate Properties.

\begin{tabular}{|c|c|c|c|c|}
\hline \multirow[t]{2}{*}{ Laboratory test } & \multirow[t]{2}{*}{ Method } & \multicolumn{2}{|c|}{ Specification } & \multirow[t]{2}{*}{ Result } \\
\hline & & Min & Max & \\
\hline \multicolumn{5}{|c|}{ Coarse Agregate } \\
\hline Bulk specific gravity (Gsb) & AASHTO T84/T85 & 2.5 & - & 2.67 \\
\hline Surface Saturated Dry gravity & & 2.5 & - & 2.69 \\
\hline Apparent specific gravity (SG) & & 2.5 & - & 2.73 \\
\hline Absorption & & - & 3 & 0.89 \\
\hline Flakiness Index & SNI 03-4137-1996 & - & $25 \%$ & $13.15 \%$ \\
\hline Los Angeles Abration & AASHTO T96 & - & $40 \%$ & $38 \%$ \\
\hline \multicolumn{5}{|c|}{ Medium Agregate } \\
\hline Bulk specific gravity (Gsb) & AASHTO T84/T85 & 2.5 & - & 2.67 \\
\hline Surface Saturated Dry gravity & & 2.5 & - & 2.69 \\
\hline Apparent specific gravity (SG) & & 2.5 & - & 2.74 \\
\hline Absorption & & - & 3 & 0.92 \\
\hline Flakiness Index & SNI 03-4137-1996 & - & $25 \%$ & $22.25 \%$ \\
\hline \multicolumn{5}{|c|}{ Fine Agregate } \\
\hline Bulk specific gravity (Gsb) & AASHTO T84/T85 & 2.5 & - & 2.67 \\
\hline Surface Saturated Dry gravity & & 2.5 & - & 2.69 \\
\hline Apparent specific gravity (SG) & & 2.5 & - & 2.73 \\
\hline Absorption & & - & 3 & 0.89 \\
\hline Clay lumps & SNI 03-4428-1997 & - & $8 \%$ & $3 \%$ \\
\hline
\end{tabular}

The natural rock asphalt deposits in Indonesia was found on Buton Island known as Asbuton or BNA (Buton Natural Asphalt). There is a huge reserve of natural rock asphalt with containing an asphalt content of 5-30\%. The size of deposits has been estimated at up to 677 million tonnes [8]. BNA still have a great chance to be utilized as partial or whole of oil asphalt substitutes in asphalt mixtures. BNA is produced by extracting Buton rock asphalt and more widely used as an modifier or additive because its very low penetration [9]. BNA-R (Buton Natural Asphalt - Rubber) is a product which consist of Buton rock asphalt extraction with crumb rubber. BNA-R consist of $60 \%$ bitumen semi extraction and $40 \%$ crumb rubber and reported has several advantages such as high adhesiveness, high softening point, high stiff modulus, high fracture resistance, long life and economical [10$11]$.

The content of BNA-R of $5 \%, 10 \%$ and $15 \%$ of total bitumen weight was chosen to modify the properties of base bitumen. The pulverised BNA-R into the smaller particle size then mixed with the base bitumen at the temperature of $140^{\circ} \mathrm{C}$ for 30 minutes and stir with the speed about 2,000 rpm to get the homogen mixture. For reducing the mixing temperature in the warm mix asphalt (WMA) the additive from material local was used. 
The natural zeolit is one of natural deposit of Indonesia was chosen after activated first. The $2 \%$ of zeolit powder added to the aggregate as a substitution of filler before hot bitumen blended. With this additive the mixing temperature and compaction temperature can be reached 15 degree lower than conventional mix asphalt (hot mix asphalt).

The dynamic shear theometer (DSR) test was performed on the bitumen before and after modify with BNA-R using $10 \mathrm{rad} / \mathrm{sec}(1.519 \mathrm{~Hz})$ frequency sweeps at the temperature between $52^{\circ} \mathrm{C}$ and $70^{\circ} \mathrm{C}$ with the increment of $6^{\circ} \mathrm{C}$ and prepared with two samples condition, viz un-aged and RTFO aged. RTFO condition is simulate the condition of bitumen in the filed when making the asphalt mixture where bitumen has been aged or called by short term aging.

The DSR test is generally used for evaluating the mechanical rheology of bitumen where the main parameter that will be analyzed from the test results are complex shear modulus $\left(\mathrm{G}^{*}\right)$ and phase angle $(\delta)$. The total resistance of a material to deformation when subjected to a sinusoidal shear stress was expressed by $G^{*}$ (complex shear modulus). $G^{*}$ consist of recoverable (elastic) and non-recoverable (viscous) components. The phase angle $(\delta)$, is an indicator of proportion of viscous and elastic components. The temperature and frequency of loading are very influencing the values of $G^{*}$ and $\delta$. Bitumen behave like viscous fluids with little capacity for recovering at high temperature and conversely at the low temperature, bitumen behave like elastic solids that completely recovery from deformation [12].

\section{Results and discussions}

\subsection{Bitumen Rheology}

The addition BNA-R to the base bitumen decreases the penetration grade of bitumen, increasing softening point and viscosity as shown in Table 4 . This corresponds to the characteristics of Asbuton that have very low penetration [8], [9]. Generally with modify the base bitumen with BNA-R, the bitumen became more stiff. The result of conventional rheology of bitumen showed that with the addition of BNA- R increase the softening point. The increase in softening point is very advantages since bitumen with higher softening point may be less susceptible to permanent deformation (rutting). This is relevant with the decreasing penetration grade of bitumen after modifying with BNA-R. The viscosity values increase with the addition of BNA-R.

Table 4. Properties of bitumen modified.

\begin{tabular}{|l|c|c|c|c|}
\hline \multirow{2}{*}{ Laboratory Test } & \multicolumn{4}{|c|}{ Content of BNA-R } \\
\cline { 2 - 5 } & $0 \%$ & $5 \%$ & $10 \%$ & $15 \%$ \\
\hline Penetration, $25^{\circ} \mathrm{C}$ & 64.20 & 55.60 & 52.40 & 50.80 \\
\hline Softening Point, ${ }^{\circ} \mathrm{C}$ & 51.50 & 52 & 53 & 53.75 \\
\hline Viscosity Kinematic at $135^{\circ} \mathrm{C}, \mathrm{cST}$ & 459.60 & 472.08 & 484.58 & 503.67 \\
\hline
\end{tabular}

The mechanical rheology of bitumen can be evaluate from the result of DSR test. The changing of complex shear modulus $\left(\mathrm{G}^{*}\right)$ and phase angle $(\delta)$ of both base bitumen and modified bitumen at frequency level of $1.519 \mathrm{~Hz}$ and at five different temperature are presented in Fig. 1 and Fig. 2 respectively. 

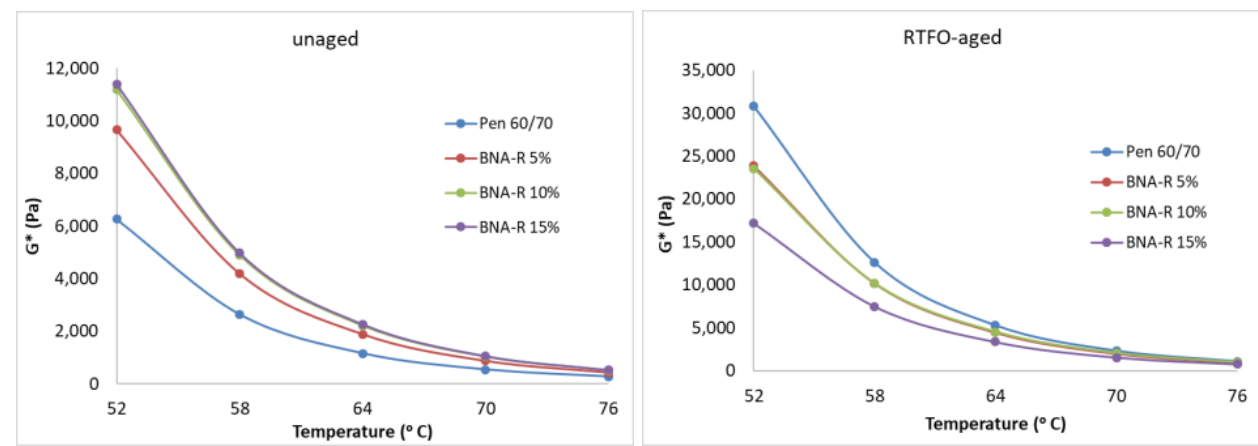

Fig.1. The changing of complex shear modulus $\left(\mathrm{G}^{*}\right)$ at unaged and RTFO-aged.
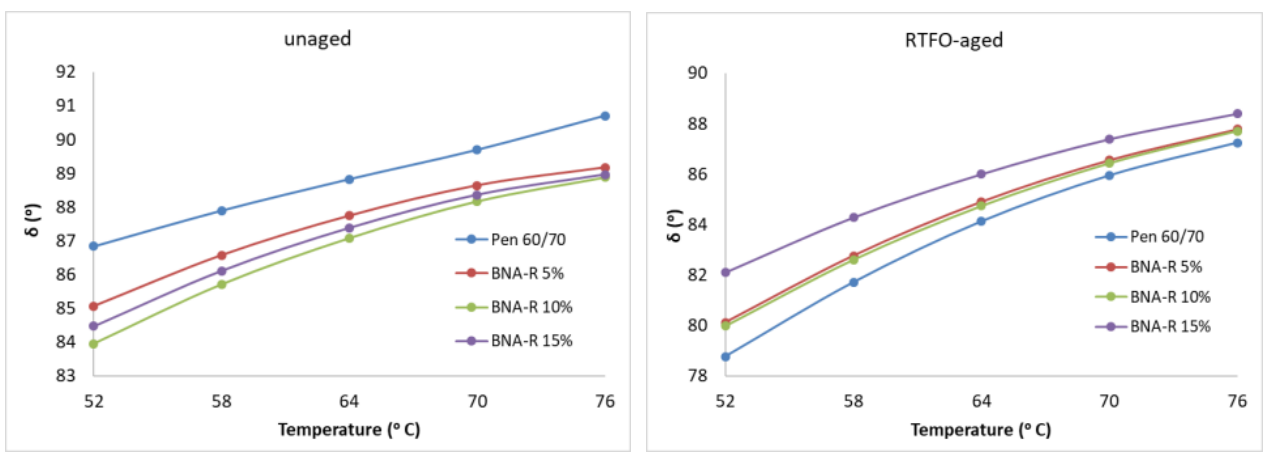

Fig.2. The changing of phase angle $(\delta)$ at unaged and RTFO-aged.

As depicted in Fig. 1, as temperature increases, complex shear modulus decreases. A decreasing in $\mathrm{G}^{*}$ indicates lower elastic part. The phase angle increases as the test temperature increases as depicted in Fig. 2. The rheology of bitumen can be evaluated by measuring two viscoelastic parameters including complex shear modulus ( $\mathrm{G}^{*}$, stiffness) and phase angle ( $\delta$, viscous or elastic indicator) throughout various test temperatures and frequencies so that the behaviour of asphalt pavement by various conditions can be predicted. From the Fig. 1 and Fig. 2, the addition of BNA-R as a modifier to the base bitumen influence the value of $G^{*}$ and $\delta$. Generally, the higher content of modifier, the higher value of $\mathrm{G}^{*}$ and lower value of $\delta$. It indicate that the BNA-R make the bitumen more stiff and elastic.

The capability of pavement to withstand the deformation or rutting is related to both binder properties and aggregate properties. The $\mathrm{G}^{*} / \sin \delta$ value is considered as a numerical indicator of rutting resistance, while higher $\mathrm{G}^{*} / \sin \delta$ values are favorable for permanent deformation resistance $[13,14]$. A high complex shear modulus $\mathrm{G}^{*}$ and low phase angle $\delta$ are both desirable for rutting resistance. Fig. 3 shows the anti rutting factor $\mathrm{G}^{*} / \sin \delta$ for both unaged and short term aging (RTFO-aged). At the low of test temperature, the addtion of BNA-R give the significant increment of $\mathrm{G}^{*}$ and $\mathrm{G}^{*} / \sin \delta$, but not at the high ones.

\subsection{Permanent Deformation Performance}

The samples of asphalt mixture was prepared base on the optimum bitumen content at the each content of modifier (BNA-R) from the Marshall test. In order to make the warm mix asphalt where the mixing and compacting temperature lower than conventional, the natural zeolit powder was used at the content of $2 \%$ as a substitution of filler of the asphalt 
mixture. The decreasing temperature with using natural zeolit reach about $15^{\circ} \mathrm{C}$ than hot mix asphalt.
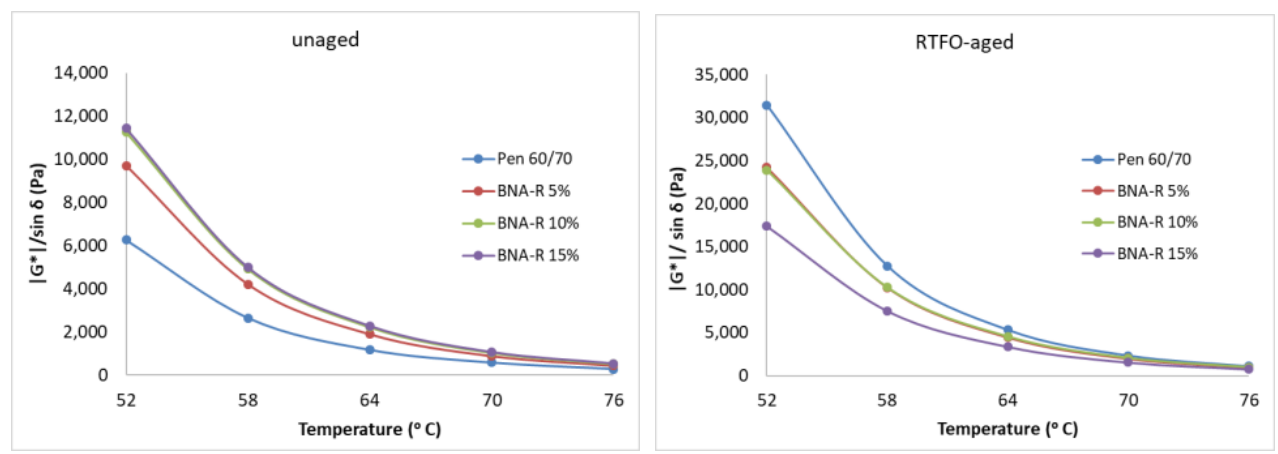

Fig.3. The changing of anti rutting factor $\left(\mathrm{G}^{*} / \sin \delta\right)$ at unaged and RTFO-aged.

To evaluate the performance of asphalt mixture to the permanent deformation criteria, the wheel tracking machine test with the extended cycles until 3 hours $(3,780$ trajectories) was used. The conventional asphalt mixture was prepared too as a comparison. Fig. 4 and Fig. 5 shows the result of the extended wheel tracking test at the test temperature of $40^{\circ} \mathrm{C}$ for hot mix asphalt and warm mix asphalt respectively.

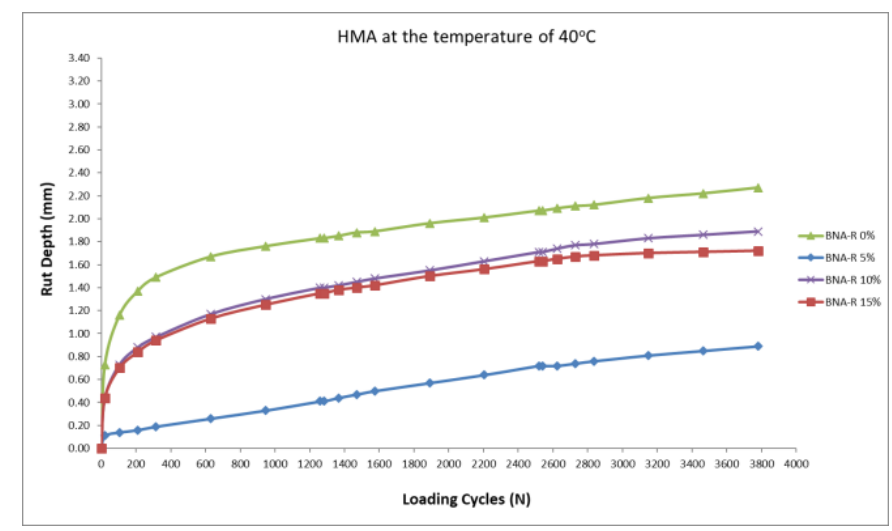

Fig. 4. The deformation of hot mix asphalt.

As depicted at the Fig. 4 and Fig. 5, the deformation (rut depth) of asphalt mixture with unmodified bitumen higher than mixture with modified bitumen both of hot mix and warm mix asphalt. Because both mixtures was prepared at the same gradation of aggregate, the performance of mixtures deformation very dependant on the bitumen properties. As mentioned above, the rheology of bitumen changed because of the addition of BNA-R especially showed in anti rutting factor $\left(\mathrm{G}^{*} / \sin \delta\right)$, this influencing the resistance of mixtures to the deformation overall. 


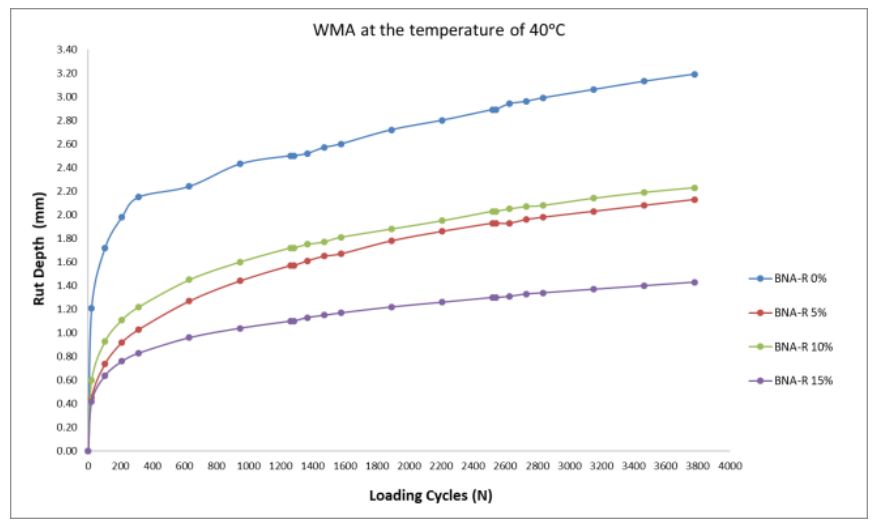

Fig.5. The deformation of warm mix asphalt.

Comparing the performance of hot mix asphalt and warm mix asphalt in the deformation, looked that the low mixing and compacting temperature $\left(135^{\circ} \mathrm{C}\right)$, the appeareance of rutting of warm mix asphalt higher than hot mix. As Fig.d in Fig. 4 and Fig. 5 , the maximum rutting of hot mix asphalt of about $2.2 \mathrm{~mm}$ but for warm mix asphalt reach of about $3.3 \mathrm{~mm}$, for mixture without modified bitumen. The reduction in rutting depth is quite significant when the mixture use modified bitumen, both of hot mixture or warm mixture.

\section{Conclusions}

Based on the tests, the conclusion of the study is the changes of the bitumen rheology can affect the performance of asphalt mixture. The decreasing of mixing and compacting temperature in the warm mix asphalt tend to lowering the capability to the resistance of permanent deformation. BNA-R as a local material from Indonesia can be used as bitumen modifier to enhance the bitumen resistance to the deformation. The composition of BNA$\mathrm{R}$ and natural zeolit as an additive for reducing mixing temperature in WMA must be suitable for keeping the ability of asphalt mixture in resist the deformation permanent.

This research was sponsored by the grant Penelitian Disertasi Doktor (PDD) from Ministry of Research, Technology and Higher Education Republic of Indonesia year 2017 with the contract number of 009/SP2H/LT/DRPM/IV/2017. The laboratory work was completed in the Material and Structure Laboratory Universitas Indonesia, Laboratory of Highway engineering and Traffic Institut Teknologi Bandung and Research Centre and Development for Road and Bridge Laboratory Ministry of Public works Republic of Indonesia. The paper was prepared with the support from Workshop dan Klinik Peningkatan Kualitas Hasil Penelitian Program Peningkatan Kapasitas Riset was held by DRPM Ministry of Research, Technology and Higher Education Indonesia collaboration with Universitas Katolik Parahyangan.

\section{References}

1. Y. H. Huang, Pavement Analysis and Design (2003)

2. J. Read and D. Whiteoak, The Shell bitumen handbook (2003)

3. S. D. Capitalo, L. G. Picado-Santos, F. Martinho, Constr. Build. Mater. 36, 1016-1024 (2012)

4. A. Topal, B. Sengoz, B.V. Kok, M. Yilmaz, P.A. Dokandari, J. Oner, D. Kaya, Constr. Build. Mater. 57, 38-44 (2014) 
5. A. Chowdhury, J. Button, Texas Transportation Institute. Texas A\&M University System. 7(2), 75 (2008)

6. X. Huang, Y. Zhang, Road Mater. Pavement Des. 11(3), 969-991 (2010)

7. S. P. Hadiwardoyo, R. Jachrizal Sumabrata, R. H. Aryapijati, N. Wahjuningsih, A. Kurnia, R. Abrar, ARPN J. Eng. Appl. Sci. 11, 24 (2016)

8. N. Suaryana, Int. J. Pavement Res. Technol. 9(5), 387-392 (2016)

9. S. P. Hadiwardoyo, E. S. Sinaga, H. Fikri, Constr. Build. Mater. 42, 5-10 (2013)

10. N. Anagi, S. P. Hadiwardoyo, R. J. Sumabrata, N. Wahjuningsih, AIP Conference Proceedings, 1855 (2017)

11. N. Wahjuningsih, S. P. Hadiwardoyo, R. J. Sumabrata, AIP Conference Proceedings, 1855 (2017)

12. B. Sengoz, L. Bagayogo, J. Oner, A. Topal, Constr. Build. Mater. 154, 1105-1111 (2017)

13. Y. Li, S. Liu, Z. Xue, W. Cao, Constr. Build. Mater. 54, 533-540 (2014)

14. A. Behl, S. Chandra, A. M. Asce, J. Mater. Civ. Eng. 29 (2012), 1-7 (2017) 